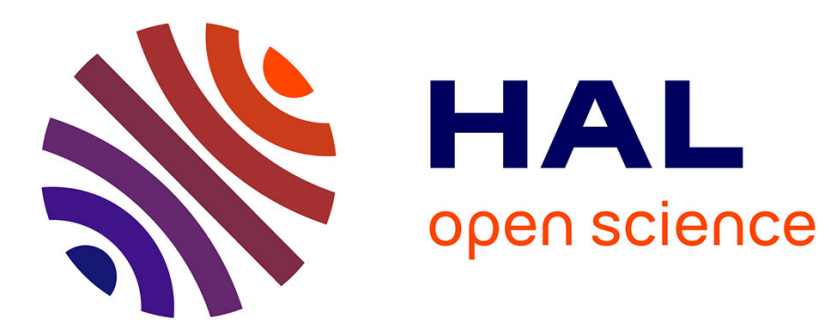

\title{
Novel liquid crystal structures in cyano bi-cyclohexanes
}

G.J. Brownsey, A.J. Leadbetter

\section{To cite this version:}

G.J. Brownsey, A.J. Leadbetter. Novel liquid crystal structures in cyano bi-cyclohexanes. Journal de Physique Lettres, 1981, 42 (6), pp.135-139. 10.1051/jphyslet:01981004206013500 . jpa-00231892

\section{HAL Id: jpa-00231892 https://hal.science/jpa-00231892}

Submitted on 1 Jan 1981

HAL is a multi-disciplinary open access archive for the deposit and dissemination of scientific research documents, whether they are published or not. The documents may come from teaching and research institutions in France or abroad, or from public or private research centers.
L'archive ouverte pluridisciplinaire HAL, est destinée au dépôt et à la diffusion de documents scientifiques de niveau recherche, publiés ou non, émanant des établissements d'enseignement et de recherche français ou étrangers, des laboratoires publics ou privés. 


\title{
Novel liquid crystal structures in cyano bi-cyclohexanes
}

\author{
G. J. Brownsey and A. J. Leadbetter \\ Chemistry Department, University of Exeter, Exeter EX4 4QD, U.K.
}

(Reçu le 14 novembre 1980, révisé le 28 janvier 1981, accepté le 30 janvier 1981)

Résumé. - Les structures des phases des cristaux liquides formées avec les trois molécules de la série

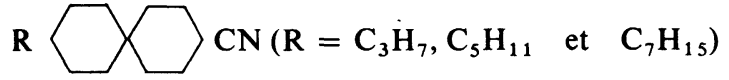

ont été déterminées. Toutes les trois donnent lieu à des phases nématiques dont les fluctuations de densité des pseudo-couches sont extrêmement faibles. Les deux plus courtes donnent lieu à des structures du type bicouche smectique $B$ dans lesquelles les queues et les groupes cyanure terminaux sont interpénétrés. Dans la structure $S_{B}$, existent également des modulations locales prononcées, probablement de nature antiphase polaire associée à une tendance à un ordre entre extrémités. Par contre, les composés cyanure du type

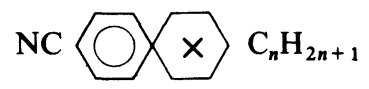

où $x$ représente soit du cyclohexane, soit un bi-cyclooctane, ont un empilement du type bicouche local semblable à celui des biphényles correspondants.

Abstract. - The structures of liquid crystal phases of three members of the series

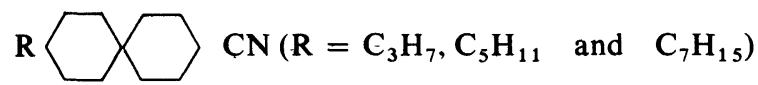

have been determined. All have nematic phases with extremely weak pseudo-layer density fluctuations and the two lowest members have bilayer smectic B type structures in which tails and cyano end groups are interdigitated. There also exist in the $S_{B}$ structures pronounced local modulations probably of a polar antiphase nature associated with a tendency to end-to-end ordering. In contrast cyano compounds of the type

where $x$ is either cyclohexane or bi-cyclooctane have a local bilayer packing similar to that of the analogous biphenyls.

Extensive investigations have already been reported of the structures of nematic and smectic phases of a variety of cyano compounds. The most common structural feature is a bilayer type structure in which the layer spacings $(d)$ (smectic) or the wavelengths $(d)$ of the damped layer-like fluctuations (nematic) exceed the molecular length $(l)$ by the length of the molecular tail. This is due to an overlapping core structure $[1,2]$. In addition, structures containing two incommensurate density waves [2], showing undulatory fluctuations [3] and exhibiting transitions between monolayer and bilayer structures have also been found $[4,5]$.

This note reports the results of simple X-ray diffraction studies of liquid crystal-forming compounds containing cyclohexane or bi-cyclooctane in place of benzene rings. The compounds studied are listed in table I together with their phase behaviour as determined by optical microscopy.

The PCH and PBCO compounds show only nematic liquid crystal phases with diffraction patterns similar to those of the cyano biphenyls : they have positive diamagnetic anisotropy and so are readily aligned using a magnetic field. The pseudo-layer spacings (Table II) exceed the molecular length by about the length of the alkyl tail, suggesting a similar core-overlapping structure to that of the biphenyls. This can be rationalized by recognizing that the average packing requires the lower area cyano group 
Table I. - Names and phase behaviour of compounds studied.

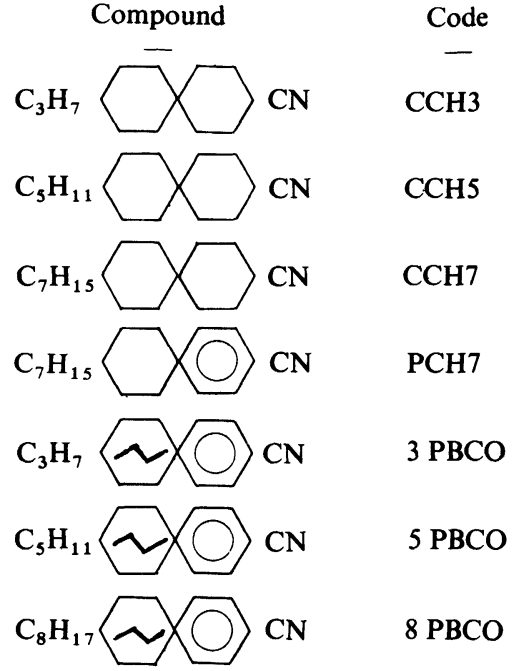

Table II. - Smectic B phase : lattice parameters.

$\begin{array}{llll}\text { Compound } & l / \AA & c / \AA & a / \AA \\ \mathrm{CN}_{\mathrm{CH}} & 16.5 & 27.3 & 5.7 \\ \mathrm{C}_{5} \mathrm{H}_{11} & 18.5 & 31.2 & 5.7\end{array}$

Nematic phase : fluctuation wavelengths parallel and perpendicular to the director.

\begin{tabular}{|c|c|c|c|}
\hline Compound & $\underline{l / \AA}$ & $\underset{-}{d_{\|} / \AA}$ & $\underline{d_{i} / \AA}$ \\
\hline $\mathrm{CN}$ & 18.5 & 27.2 & 4.9 \\
\hline $\mathrm{CN}$ & 20.7 & 31 & 4.9 \\
\hline $\mathrm{C}_{7} \mathrm{H}_{15}$ & 20.0 & 29 & 4.5 \\
\hline $\mathrm{C}_{3} \mathrm{H}_{7}$ & 16.5 & 22 & 4.9 \\
\hline $\mathrm{CN}$ & 18.5 & 24 & 4.9 \\
\hline 7 & 21.5 & 31 & 5.0 \\
\hline
\end{tabular}

to be adjacent to the more bulky cyclohexyl or bicyclooctane ring so that steric factors can favour this packing.

The $\mathrm{CCH}$ series show a highly unusual phase behaviour in that the compound with the shortest tail has the greatest smectic stability while $\mathrm{CCH} 7$ shows only a nematic phase. These compounds all possess negative diamagnetic anisotropy so they cannot be preferentially aligned using magnetic fields. However, the S-1 phases spontaneously tended to form monodomains when cooled from the nematic so that by taking a series of stationary-sample flat film photographs, a good picture of the reciprocal space of this phase could be constructed. Most work has been done on $\mathrm{CCH} 3$ for which representative photographs of the S-1 phase are shown in figure 1 and schematically summarized in figure 2 . However, very similar results have been obtained for the S-1 phase of CCH5. The S-1 phases of the two compounds are of identical structure and the numerical data describing these structures are summarized in table II. We have, so far, been unsuccessful in taking X-ray photographs of the monotropic S-2 phase of $\mathrm{CCH} 3$ because the sample always crystallized.

$\mathrm{X}$-ray photographs taken with the incident beam approximately normal to the layers of the S-1 phase show a clear hexagonal symmetry (Fig. 1a), but only the first ring in reciprocal space has appreciable intensity. With the beam parallel to the layers, photographs like that of figures $1 b$ and $c$ are obtained. The observed Bragg reflections are readily indexed as a hexagonal bilayer structure, the observed reflections (hexagonal axes) being 002, 004, 006; 100,101, 102, $103,104,10 \overline{1}, 10 \overline{2}, 10 \overline{3}, 10 \overline{4}$ (with 6 equivalent sets centred on $1 \overline{10}$ etc.).

The S-1 phases are thus bilayer $S_{B}$ structures of types seen previously for several other compounds $[6,7,8]:$ the absence of $00 l$ reflections with $l=2 n+1$ and the relative intensities of the $10 \mathrm{l}$ reflections show that the structure consists of an ABA... type packing of equivalent half-layers [6]. The bilayer structure is thus associated with layer packing rather than with polar ordering. Indeed, a comparison of layer spacings and molecular lengths shows that the ABA... packing is associated with a pronounced interdigitation of the molecules. Thus the layer spacings $(c / 2)$ are shorter than the molecular lengths $(l)$ by about $2.9 \AA$ in both cases and this is very close to the effective length of the $-\mathrm{CN}$ group (and of the $-\mathrm{C}_{3} \mathrm{H}_{7}$ group). Noting that the area occupied by a $\mathrm{CN}$ or short alkyl chain 


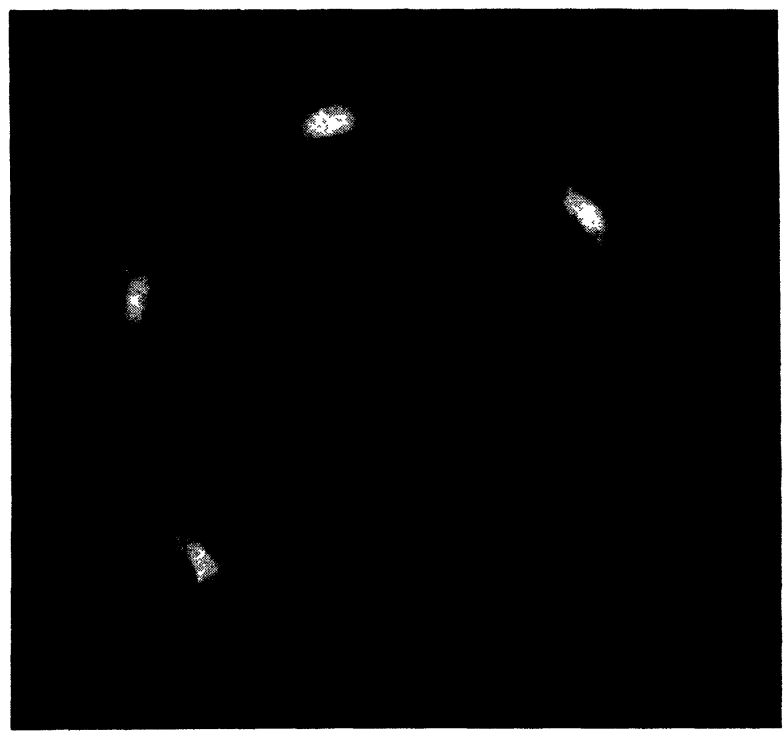

a)

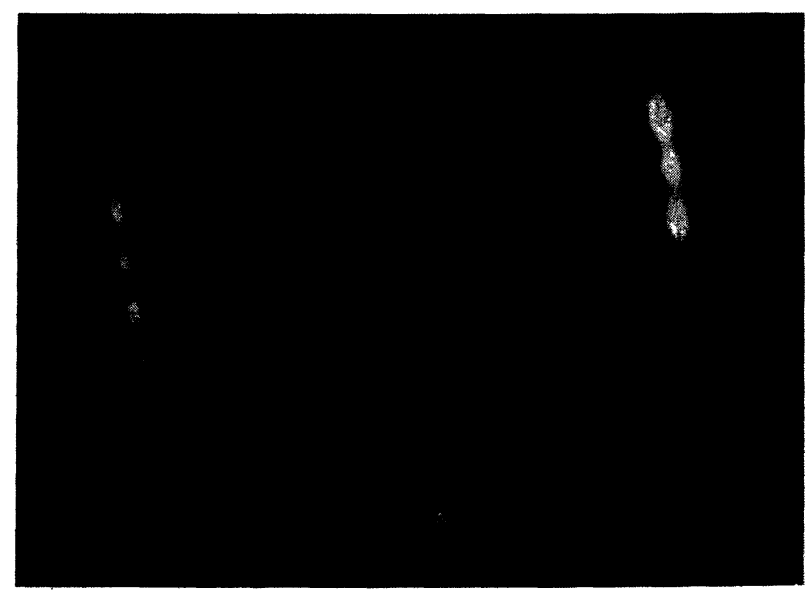

b)

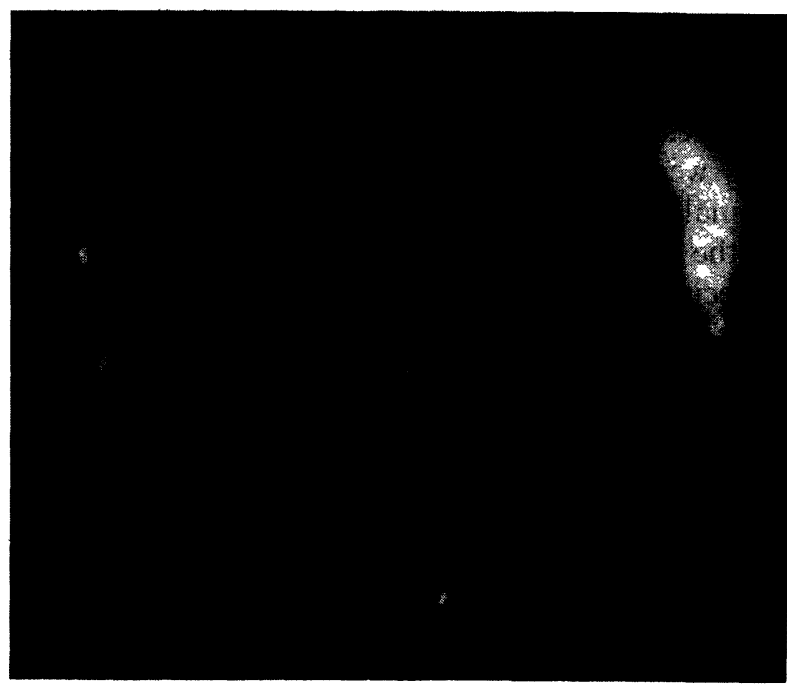

c)

Fig. 1. - X-ray photographs of the S-1 (Smectic B) phase of CCH3 : a) incident beam approximately normal to the layers; b) and c) incident beam parallel to the layers.

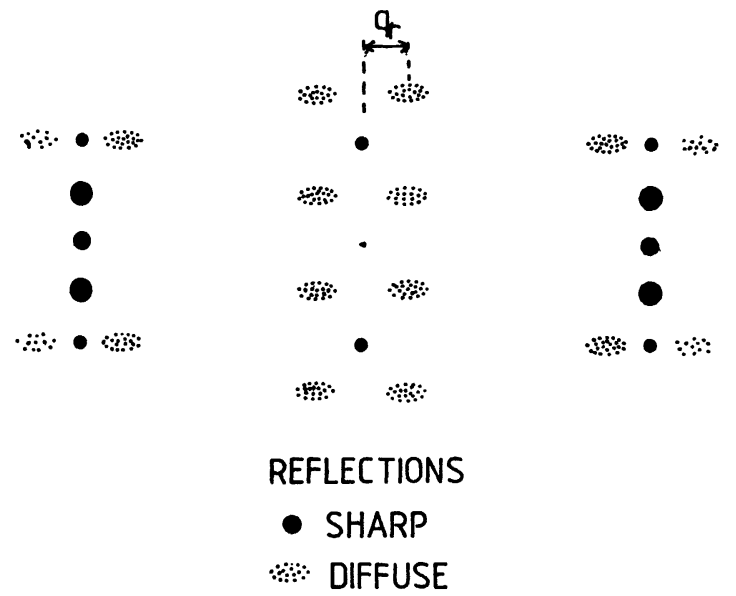

Fig. 2. - Schematic representation of the $h 0 l$ plane of reciprocal space for the $\mathrm{S}_{\mathrm{B}}$ phase of $\mathrm{CCH} 3$ (and $\mathrm{CCH} 5$ ).

is about half of that required by a cyclohexane ring, this suggests a structure in which on average the molecules have random end-to-end packing with interdigitation of the $-\mathrm{CN}$ and alkyl groups. This interdigitation is complete for the $-\mathrm{C}_{3} \mathrm{H}_{7}$ groups which have essentially the same size as the - $-\mathrm{CN}$ group, and the structure for $\mathrm{CCH} 3$ is shown in figure 3. However, for $\mathrm{CCH} 5$ the overlap is less than the total chain length of the $-\mathrm{C}_{5} \mathrm{H}_{11}$ unit and this structure is apparently unstable for the $-\mathrm{C}_{7} \mathrm{H}_{15}$ case in which no $S_{B}$ phase is observed. This may be due to the fact that with increasing tail length, the angle between core and tail axes together with the thermal disorder make this type of packing sterically impossible - it can only occur for short tails. This structure therefore has two unique features : firstly, it is the first truly interdigitated «smectic» structure and secondly, it is the first case in which smectic stability is seen to be enhanced for a trend of decreasing molecular length. It should be emphasized also that this is an example of a $S_{B}$ phase which is truly crystalline [9]. It is not surprising in view of the special structure of this $S_{B}$ phase that it has not been found to be completely miscible in all proportions with the

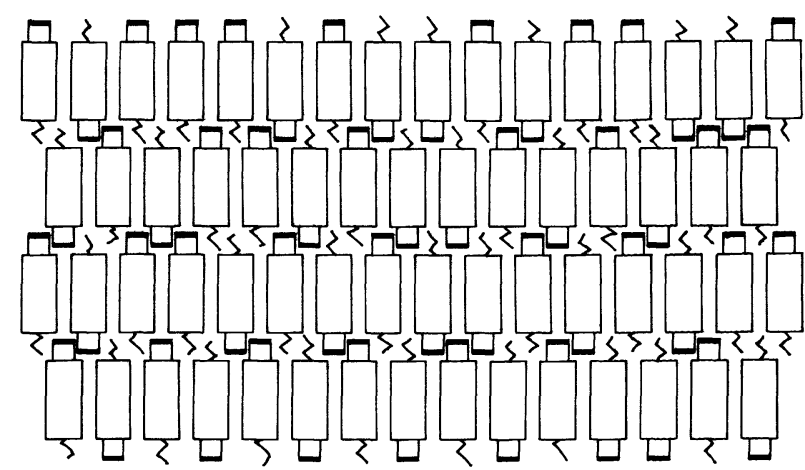

Fig. 3. - Structure of the $\mathrm{S}_{\mathrm{B}}$ phase of $\mathrm{CCH} 3$ (and $\mathrm{CCH} 5$ ) showing ABA... packing of hexagonal layers and the random head-to-tail disorder of the average structure. 
$S_{B}$ phase of any other compounds [10]. Complete miscibility can of course only be a positive criterion for phase identity and immiscibility proves nothing about the phase type.

The above analysis of the Bragg scattering has clearly determined the average structure of the $\mathrm{S}_{\mathrm{B}}$ phases of the $\mathrm{CCH}$ compounds. However, there also exists strong diffuse scattering which reveals the nature of fluctuations in local order within this structure. The most well defined diffuse scattering (additional to the strong scattering around the Bragg spots) consists of flat rings of scattering located on the odd layer planes at $\mathbf{q}_{z} / \mathbf{c}^{*}=1$ and 3 together with a spread of wave vectors parallel to the layer planes centred on $\mathrm{q}_{\mathrm{r}} / \mathrm{a}^{*} \approx 6$ (see Fig. 1).

In addition, there is strong but less well-localized diffuse scattering around the 10l-type rows at the $l=2$ level. This scattering is displaced relative to the strong 101 type Bragg peaks by a vector similar to these relating the diffuse scattering near the $00 l$ row with the $00 l$ spots, and overall the diffuse pattern may be described as satellite scattering associated with the Bragg peaks by a vector $\mathbf{q}_{\mathrm{s}}$ (where $\mathbf{q}_{\mathrm{s}}=\mathbf{c}^{*}+\mathbf{q}_{\mathrm{r}}$ ), which makes an angle of about $45^{\circ}$ with $\langle 00 l\rangle$. Such scattering implies a modulation of the structure and the diffuse nature of the scattering shows the modulations to be of a local character, having a finite correlation length $\xi$ with a value perpendicular to the layers of $\xi_{\perp} \sim 360 \AA$ while $\xi_{\|} \sim 70 \AA$ or about 2 wavelengths. The fact that the diffuse scattering appears to consist of rings suggests that the modulations have no strongly preferred directions in the $x y$ plane.

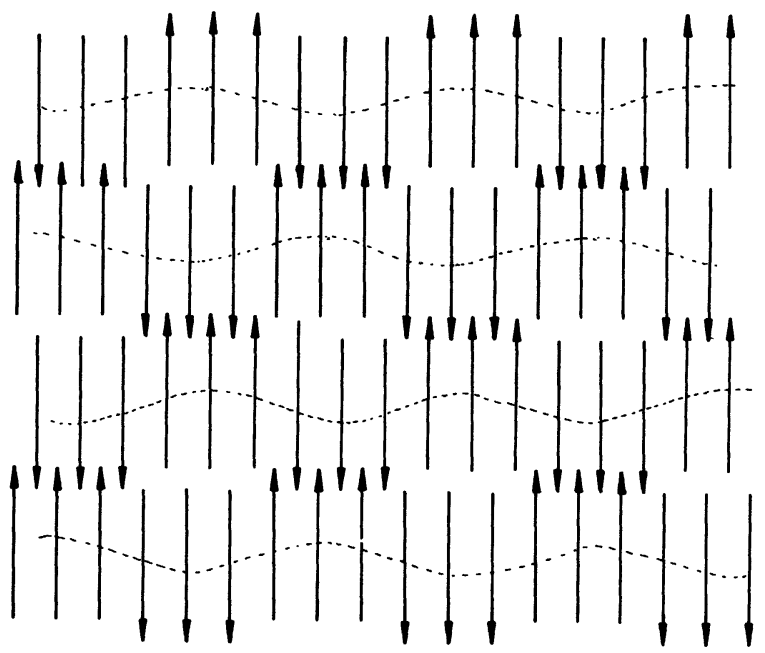

Fig. 4. - Schematic representation of suggested modulations of the $S_{B}$ structure. The arrows represent the $-\mathrm{CN}$ end of the molecules and the waves represent possible centre of mass displacements. For simplicity a perfect antiphase superlattice is shown here but in reality the ordering is weak with correlation lengths given in the text.
Consideration of the molecular constitution and the average structure leads us to speculate that the modulation arises from a tendency of the molecules to polar ordering - i.e. antiparallel association of $-\mathrm{CN}$ groups - (cf. Fig. 3). The diffuse pattern around the $\langle 001\rangle$ direction suggests that the local structural modulation may be based on some kind of face centred (antiphase) superlattice of the type illustrated schematically in figure 4 (but any such structure must in fact be disordered in the $x y$ plane over the sample as a whole). Such a superlattice would give additional reflections at

$$
\mathbf{q}=\mathbf{q}_{\mathbf{z}}+\mathbf{q}_{\mathrm{r}} \text { with } \mathbf{q}_{\mathbf{z}} / \mathbf{c}^{*}=2 n+1 \text { and } \mathbf{q}_{\mathrm{r}}=2 \pi / \lambda_{\mathrm{s}}
$$

where $\lambda_{\mathrm{s}}$ is the wavelength of the antiphase fluctuation. The polar ordering may well also be combined with centre of mass displacements as indicated in figure 4 but the absence of any diffuse scattering on the zero level shows that any displacements are parallel to $\langle 00 l\rangle$. Confirmation of the detailed nature of the structural fluctuations must await more quantitative calculations.

The diffraction pattern of the nematic phases of all three $\mathrm{CCH}$ compounds show that the damped density waves parallel to the director are very weak, in comparison to those in cyanobiphenyls, $\mathrm{PCH} 7$ and the PBCOs. Indeed for $\mathrm{CCH} 3$ no scattering from this source is measurable, while it becomes more intense from $\mathrm{CCH} 5$ to $\mathrm{CCH}$. The wavelengths of these density fluctuations are about $50 \%$ longer than the molecular length (see Table II) and while this $d / l$ ratio is comparable to that for other cyano compounds, the overlapping core structure established for the cyanobiphenyls may be ruled out for the $\mathrm{CCH}$ compounds on steric grounds because of the extremely bulky cores.

We suggest that dimer formation may be important in the nematic phase resulting in effective molecular units with much longer cores than for the monomer. In any case the tendency to pseudo-layer formation increases with tail length in the usual way and is very weak indeed in the lowest homologue. The anomalous behaviour is the formation of the $S_{B}$ phase for the shorter homologues and we attribute this to a special combination of dipole-dipole attraction and steric factors as discussed above.

Acknowledgments. - We are grateful to the Ministry of Defence for financial support, to Merck, Darmstadt for supplying the $\mathrm{CCH}$ compounds and to Prof. G. W. Gray, University of Hull for supplying the remaining materials. 


\section{References}

[1] Leadbetter, A. J., Frost, J. C., Gaughan, J. P., Gray, G. W. and Mosley, A., J. Physique 40 (1979) 375.

[2] Brownsey, G. J. and Leadbetter, A. J., Phys. Rev. Lett. 44 (1980) 1608.

[3] Hardouin, F. and Levelut, A. M., J. Physique 41 (1980) 41.

[4] Hardouin, F., Levelut, A. M., Benattar, J. J. and Sigaud, G., Solid State Commun. 33 (1980) 337.

[5] Hardouin, F., Sigaud, G., Archard, M. F. and Gasparoux, H., Phys. Lett. 71 A (1979) 347.

[6] Leadbetter, A. J., Frost, J. C. and Mazm, M. A., J. Physique Lett. 40 (1979) L-325.
[7] Leadbetter, A. J., Mazid, M. A., Kelly, B. A., Goodby, J. W. and Gray, G. W., Phys. Rev. Lett. 43 (1979) 630.

[8] Leadbetter, A. J., Mazid, M. A. and Richardson, R. M., Liquid Crystals, Ed. S. Chandrasekhar (Heyden \& Son, London) 1980, p. 65.

[9] Gane, P. A. C., Leadbetter, A. J. and Wrighton, P. G., Proc. VIII. Int. Liq. Cryst. Conference, Kyoto 1980. Mol. Cryst. Liq. Cryst. (In press).

[10] Gray, G. W., Private Communication, 1979. 